\title{
ANTHROPOECOLOGY: THE ECOLOGICAL ETHICS IN AMITAV GHOSH'S THE HUNGRY TIDE
}

\author{
Prof Dr Avinash Y. Badgujar
}

Arts, Commerce \& Science College, Jalgaon (Maharashtra), India

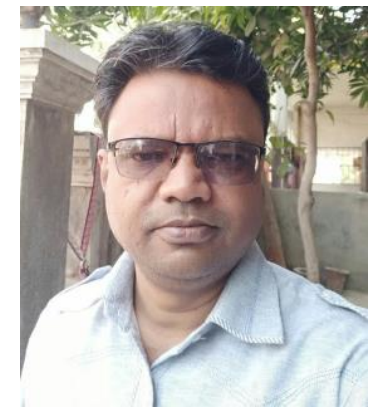

PROF.DR.AVINASH Y.BADGUJAR

\section{Keywords: Ecological Ethics,} Anthropological Surroundings, Anthropoecology.

\begin{abstract}
A B S T R A C T
The prime activity of an individual or group is determined by the necessity of interaction with other individuals or groups in the diversity of anthropological surroundings. It manifests itself in the participation of individuals with their surrounding ecosystems, including culture and physical conditions of life. Anthropoecology studies such interactions. Natalya Haldeyeva points out that anthropology as a discipline studies "the laws of interaction between human communities and the systems of natural, social and other factors, as well as the coevolution of humans with their environment, in the process of adaptation."(I) It is emphasized that anthropological and ecological approaches are the best of all the approaches to study the principles of reciprocity of development of an individual and the surrounding reality. The anthropoecological system links and interacts with the classical scientific disciplines such as biology, ecology, cytology, geology, ethology and mythology.
\end{abstract}

Citation: Avinash Y. Badgujar(2018). Anthropoecology: The Ecological Ethics In Amitav Ghosh's The Hungry Tide. International Journal of Advanced Multidisciplinary Scientific Research (IJAMSR ) ISSN:2581-4281 Vol 1, Issue 6, August, 2018, \#Art.615, pp 44-50

\section{Introduction}

In The Hungry Tide, Ghosh describes the bioregion the Sunderbans with its unique history, geography, nature and landscape. Bioregionalism the term indicates in its purview "an aspiration to respect and restore natural systems." (2) The Sunderbans is half water and half land.
It is the place that had been alternately inhabited and deserted. The landscape of the Sunderbans is frequently threatened by cyclones, crocodiles, tidal waves; lack of fresh water, tigers and poisonous snakes. The Sunderbans is the largest mangrove forest in the world. It is also known for Royal Bengal Tigers. Out of total land area, two third of its land occupies the southwest corner of Bangladesh and remaining one third is in India, the south east of West Bengal. The flora and fauna of the 


\section{International Journal of Advanced Multidisciplinary Scientific Research (IJAMSR) ISSN:2581-4281}

landscape is famous for the tigers, the river dolphins and the fish. There are more species of fish in the Sunderbans than could be found in the whole continent of Europe. In the postcolonial period, the ecologists wanted to restore, respect and preserve the natural system of this bioregion. Therefore, the government forcefully evacuated the Morichjhapi Island, which was acquired by the refugee settlers. The wildlife biologist emphatically argued that the Sunderbans is the only mangrove forest of India, where tigers are in sufficient numbers so the efforts should be made to save this endangered species.

\section{Theme}

The Hungry Tide provides the detail information about the ecosystem of the Sunderbans with its variety and magnificence. Ghosh as an anthropologist "exploits his scientific knowledge to construct a wonderful series of narratives of natural artistry: how the river paints its own landscape; how the trees encapsulate its own history." (3) The unique natural zone of the Sunderbans also has the unique history. The Sunder bans mean the "beautiful forest" known for the Sundari trees, a species of mangrove. The mangrove forest is unique and different from other woodlands. There are no giant or vine looped trees, no ferns, nor wild flowers, nor chattering monkeys and cockatoos. The leaves of mangrove are touch and leathery, its branches and foliage is often thick. There trees serve as a barrier against the fury of nature. They absorb the initial onslaught of cyclone waves and tidal surges. The leathery leaves of the mangrove are used by the inhabitants for making huts. Another species of mangrove tree is jargon tree that breaths through its spears like ventilators.
The relationship between man and nature is altered one. Nature is usually molded, utilized and exploited by humans, but in the Sunderbans there is very limited scope to mould nature. On the other hand it is nature that moulds the accomplishments of peoples by huge tidal waves, cyclones and tsunamis. Here not only the nature is hostile to the humans, but also the animals, especially the tigers that are known for their man eating habits. There are some animals that are benevolent to the fishermen as the case with the dolphins that show the way of fish.

The landscape of the Sunderbans is unpredictable, where "the tides create new land, overnight mangroves begins to gestate," (4) and the old land gets washed away in the tidal waves. The Sunderbans' ecosystem of mangrove forested island and mudflats, represents the constant transformation it undergoes, because of daily tidal waves, with sections of land submerged temporarily and seawater and fresh water intermingling. The tide country is a harsh landscape, full of peril and death in many forms. "Every year, dozens of people perish in the embrace of that dense foliage, killed by tigers, snakes and crocodiles." (HT, 8) It shows that the novel displays a kind of 'dialogue' between the human habitat and the ecological set up that leads to a complex interaction between man and nature. Sometimes the man-nature relationship appears to be harmonious as in case of dolphins showing the ways of fish to the fishermen and sometimes the relationship appears to be hostile as there is constant threat of animals, cyclone and storms.

In the bioregion of the Sunderbans each species functions for the stability of the community. For instance, the role played by the crabs in the tide country ecosystem. They represent the system's biomass and they outweigh even the trees and the leaves. Crabs are 


\section{International Journal of Advanced Multidisciplinary Scientific Research (IJAMSR) ISSN:2581-4281}

the 'keystone species' of the entire ecosystem of the Sunderbans. The crabs perform the role of sanitation department and a janitorial team to keep the mangroves alive by removing their leaves and litter. Therefore, some ecologists said that the "forests should be named after crabs rather than mangrove since it was they certainly not the crocodile or the tiger or the dolphin who were the keystone species of the entire ecosystem." (HT, 149-50) Moreover, the crabs laundered the mud in which they lived scrubbing it grain by grain. Their appearance forms microscopic brushes and spoons. The crabs also provide the livelihood to the fishermen as they are edible. The example of the crabs suggests that every species and organism perform its function suitable to the ecosystem.

The Hungry Tide, the novel, reads like a scientific treatise as Ghosh exhibits highly professional scientific descriptions related to cetology. In this sense Ghosh appears to be anthrop-cetologist. Cetology involves the study of marine mammals. A principal figure of the novel is a cetologist, named Piyali Roy. She is a research student, who studies marine mammals. Her field of expertise concerns the freshwater river dolphins that are to be found in Asia's great waterways the Mekong, the Irrawaddy, the Ganges, in the Bay of Bengal. She is an Indian immigrant living in the United States, at Seattle, she has little contact with her parent's native Bengal but she has come to India to conduct a survey of marine mammals in the Gangetic delta. There is initial confusion regarding the Orcaella, they were thought to be two different species, but later on it was found that there was only one species, 'Orcaella brevirostris.' However, there were two types of populations of Orcaella, the coastal and the riverine populations. These two populations of the single Orcaella species did not mix that is from coast to riverine and from riverine to coastal.

Piya studies the dwindling breed of Irrawaddy dolphin. These dolphins exhibit familiar behavioral patterns that are shooting water from the mouth. The spitting behavior is one of the features of Irrawaddy dolphins. They also toss the fish into the air before catching it in their mouth. Ghosh informs that "the propensity to play with prey was a family trait-Orcaella shared it with its relatives, the killer whale."(HT, 142) Piya finds out that these dolphins have developed the habit to linger behind, it makes her think that if the dolphins are adapting their behavior to suit the tidal country and to its ecology. But later on she discovers that the dolphins create an underwater pool and gather in order to hunt the herd of fish; "like rabbits uprooting a harvest of carrots, the dolphins were picking the fish from riverbed." (HT, 177

78) This habit of the dolphins reminds Piya her visit to Mandalay and her meeting with the fishermen and the herding of fish with the help of dolphins. The fishermen in order catch the fish beat the drums behind the dolphins and cast net, the dolphins get pushed forward by the net, while the fish get pushed into the net in a great number. It surprises Piya, she begins to think: "Did there exist any more remarkable instance of symbiosis between human beings and population of wild animals?" (HT, 179) The fishermen cast net fishing with the help of dolphins indicates that as if the fishermen and dolphins communicate through visual signals during fishing. The fishermen "sat listening companionably to the Oracaella as they circled around the boat." (Ht, 166)In the ecosystem and the bioregion even the simplest creatures in the form of dolphins follow the complicated and highly sophisticated pattern of behavior, and the local inhabitants in the form of 


\section{International Journal of Advanced Multidisciplinary Scientific Research (IJAMSR) ISSN:2581-4281}

fishermen can understand the behavioral pattern of the dolphins.

In her scientific research Piya discovers the behavioral pattern of the dolphins that suit the ebb and flow of the tide country. The dolphins migrate daily, early in the morning they come to the mouth of the river by crossing the lake and in the evening they return to the lake. In their daily migration they cross the distance up to 1300 kilometers upstream in major rivers. The migration also changes seasonally and is influenced by water levels. Dolphins move in the tributaries during high water and back into the lake when water levels recede. When several dolphins congregate in the low tide, Piya thinks that there is another 'pool' of the dolphins while Fokir's face indicates that "something was not quite right." (HT, 370) The inhabitant Fokir can understand the message of the dolphins as "they were reluctant to return to their pool while one of their numbers lay dead in plain view." (HT, 371) Here the dolphins can sense the approaching danger in the form of cyclone, while Fokir was thinking that something is wrong but the danger of cyclone was not realized by him. It indicates that in the ecosystem the species can interact among themselves while the inhabitants like Fokir has the better understanding of the ecosystem, its species and the behavior of the species. On the other hand the cetologist, Piya comes to know that the human beings have tried to underestimate the animals. Therefore, at the end of the novel Piya decides to come back to Lusibari and plans to begin a conservation project with funds from conservation and environmental groups.

The Hungry Tide reveals the scientific temperament of Ghosh related to Scientology and ethology in his author's notes, Ghosh informs that he accompanied Isabel Beasly, research student of
Scientology from James Cook University to make a survey expedition on the Mekong and the Irrawaddy dolphin. He also travelled in the tide country with Annu Jalats, a scholar widely known for her personal courage. He had a month long travelling with her on the Mekong River in Cambodia for studying the river dolphins. In an interview with Rahul Bose, Ghosh expresses his thoughts about anthropology, travel and fiction:

I found anthropology very interesting in many ways, especially because it allowed me to travel which was always been very fundamental to my work... I started writing fiction. For me, it's the most comprehensive form. You can put everything in it. It can contain anthropology, it can contain history, geography, ecology, you name it. ${ }^{(5)}$

It indicates that Ghosh has the better understanding of the genre novel. His novel contains the wide variety of genres that include anthropology, ecology, history, geography, ethology and mythology.

Ethology is a science that "study animal behavior." (6) Piya with the help of Fokir's indigenous knowledge comes to know certain behavioral pattern of dolphins. Fokir, the local inhabitant has the river in his veins; he knows the routes of the dolphins. He takes Piya into every little creek and gully where he had ever seen a dolphin. Fokir's indigenous knowledge of the bioregion and ecosystem to catch crabs and fish is very effective. It suggests that he has the deep knowledge of the species living in the tide country. He is familiar with the behavior of the animals. His "abilities as an observer are really extraordinary." (HT, 290) Moyna Fokir's wife wonders when Piya, a cetologist wants the help of Fokir who is illiterate. Piya can not hide her amazement: "I've never met anyone with such an incredible instinct: it's as 


\section{International Journal of Advanced Multidisciplinary Scientific Research (IJAMSR) ISSN:2581-4281}

if he can see right into the river's heart." (HT, 289) Piya discovers the behavioral pattern of the dolphins, and their adaptation of behavior to suit the ebb and flow of water that opens up endless possibilities before her. She decides to proceed further in the investigation of dolphin project and she is ready to give up her life for the cause.

To some extent the behavioral pattern of the dolphins understood by Piya, while Fokir has the indigenous knowledge of the bioregion. But there are some animals whose behavior remain a mystery even for the inhabitants. The tiger attacks on human beings and the reasons related to it are mysterious. There are some ethologists who tried to enlist the theories that are cited as reasons for the tiger attack. One of the reasons is that if the tiger is unable to hunt a prey than in the abnormal circumstances the tigers attack human beings. Another reason is related to the scent of the dead animals and human beings, those who get washed away, thereby confusing the territorial instinct of the tigers. The German naturalist thought that due to lack of fresh water, the tigers preferred the human flesh. So in the Sunderbans the Forest Department provided the pools of fresh water for the tigers. But it made no difference, the tiger attacks continued as it was. Another theory was conditioned in the form of making clay models of human beings; thinking that the tigers would get wounded when their attack on the models. This method worked for a short while, the attacks went as usual. The inhabitants came with an ingenious idea that the tigers attacked behind the backs of human beings, so they decided to wear masks on the back of their heads. Much publicity was made about this experiment. But the Tigers had no problem with discriminating masks and faces. These experiments and theories of the ethologists reveal that it is difficult to study the animal behavioral pattern; rather these examples raise a question whether "the tigers are actually able to think these things through?" (HT, 261)These examples reveal that how the tiger plans, follow, stalk and then attack the prey.

In this novel Ghosh presents the scenes of tiger and crocodile attacks in all its vividness. Asar Chowdhury considers that The Hungry Tide is "faithful to Ghosh's anthropological roots, about the co-existence of humans and man-eating tigers and dolphins in a volatile and dangerous eco-system." (7) In the tiger attack, the killing of Kusum's father is described in detail. The scene is witnessed by Kusum herself. Her father crossed the river in order to collect firewood. Kusum was standing on the bank of the river. She saw the tiger hiding in the trees so she cried; the whole village gathered there, they tried to catch the attention of Kusum's father. But their efforts proved in vain as the wind was blowing in the wrong direction. The tiger attacked her father and pulled his body in the deep jungle. Ghosh writes that:

So great was its confidence that in the last stretch, it actually broke cover and went racing along the shore, in full view of the far shore; intent on its prey, it no longer cared about concealment. (HT, 114)

The attack of crocodile is more horrible as compared to a tiger. Piya was saved by Fokir from the crocodile attack. He pulled her wrist from the water and threw her outside. She was shocked to see the crocodile with its interlocking teeth. Kanai also undergoes the pains of death handed out by the tiger and the crocodile. It is Fokir who makes Kanai to brood over death. The tiger seems to be merciful as death is instant "you felt no pain when it happened you were dead already of the shock induced by tiger's roar, just before the moment of impact" (HT, 352), while the attack of crocodile is 


\section{International Journal of Advanced Multidisciplinary Scientific Research (IJAMSR) ISSN:2581-4281}

horrible and terrible. It drags its prey into the water. A crocodile will keep you alive until you drown;" it won't kill you on land; it'll drag you into the water while you are still breathing." (HT, 353)In the crocodile attack the remains of the people are not found.

In his anthropological survey Ghosh presents the issue of man animal conflict. There are two sides of man-animal conflict. The first is animal's' attack on humans and the other are humans' attack on animals. In the colonial regime Sir Daniel Hamilton, a visionary Scotsman, founded a utopian settlement in the Sunderbans. At the beginning, on this place everyone was helpless in the face of nature and therefore on an even footing, most of the tigers of the Sunderbans were "man-eaters" and the destruction of as many tigers as possible appeared to the only way of reducing causalities. The encounter with the beast on the ground, however, was mostly left to the inhabitant hunters who were incompetent and unskilled. So Sir Daniel Hamilton adopted a policy of rewards for killing a tiger or a crocodile. For instance, Horen's uncle Bolai, who had killed a tiger was rewarded two bighas of land in Lusibari. "For years afterwards, Bolai was the hero of the land." (HT, 55)For number of years the tiger killing habit went on unheeded, until the government in the postcolonial period took the steps to preserve the tiger population; "islands were forcibly depopulated in order to make room for wildlife conservation project." (HT, 63)

The conflict between the indigenous people of the Sunderbans and the tigers is described by Ghosh in a vivid way. A tiger is trapped in a livestock pen while trying to carry away a calf. An angry mob quickly gathers and attacks the animal with sharpened staves. A boy thrusts a sharpened bamboo pole through a window and blinds it. Fokir also gets involved with the mob and participate in killing. Piya and Kanai want to save the tiger, but they remain helpless in the face of the hostile crowd. The event throws light on the ecological issue that continues to feature prominently in global debates on the management of nature. It raises a question as to which life is an important man or beasts. Ghosh answers that if there is horror in the scene, man killing tiger, then there is equal horror too in the scene of tiger killing man, and further adds that:

$$
\begin{aligned}
& \text { If there were killings on that scale } \\
& \text { anywhere else on earth, it would be called } \\
& \text { genocide, and yet it goes almost } \\
& \text { unremarked: these killings are never } \\
& \text { reported, never written about in the } \\
& \text { papers. And the reason is just that these } \\
& \text { people are too poor to matter. We all know } \\
& \text { it, but we choose not to see it. (HT, 325) }
\end{aligned}
$$

The issue of the man-animal conflict in the Sunderbans has its roots in the policy adopted by colonial and postcolonial state in India. The colonial forest policy is influenced by global capitalism that led to dislocation and displacement of the local people. In the postcolonial period, the project of tiger conservation further increased their misery. The inhabitants were deprived the right of using the forest which has been preserved only for animals. The government neglected the enormous knowledge of the inhabitants about their ecosystem and the wildlife. All these reasons are responsible for man animal conflict in the Sunderbans.

The relationship between man and nature appears to be less harmonious in the Sunderbans. Nature seems to less generous and more hostile to the inhabitants. "There is no prettiness here to invite the stranger in." (HT, 8) There is always the threat of the rivers, storms and cyclones. To some extent the mangroves serve as barrier 
against cyclonic winds, waves and tidal surges. The single stroke of wind can destroy the whole town. The minor storm hurled Canning and "in a matter of hours, the town was all but gone; only the bleached skeleton remained." (HT, 310)There were huge waves of water more than twelve meters in height. The Nirmal's diary contains the effects of the storm; in fact, it was a tsunami:

\begin{abstract}
The waters rose so high that they killed thousands of animals and, carried them upriver and inland. The corpses of tigers and rhinoceroses were found kilometers from the river, in rice-fields and in the village pond. There were fields covered with feathers of dead birds. And as this monstrous wave was travelling through the tide country racing towards Kolkata, something else happened-something unimaginable. $(H T, 219)$
\end{abstract}

\section{Conclusion}

Ghosh uses Duino Elegies of Rainer Maria Rilke to describe the peculiar condition of human beings in the Sunderbans. They are alienated from nature and animals. The human beings are not at home in their "translated" world.

\section{References}

1) Natalya I. Haldeyeva and Alexander A. Zubov, Anthropoaesthetics as an Aspect of Anthropoecology, Journal of Physiological Anthropology and Applied Human Science, Vol.24, No.4, 2005, p.351

2) U. Sumathy, Ecocriticism in Practice, Sarup Publications, New Delhi, 2009, p.59

3) Greg Garrard, Ecocriticism, Routledge, London, and New York, 2007, p.73
4) Amitav Ghosh The Hungry Tide, Ravi Dayal, New Delhi, 2004,p,8 (All subsequent references are from this edition.)

5) Verve Online, Reading between the lines, Amitav Ghosh in conversation with Rahul Bose, 28 May, 2011

http://www.verveonline.com/30/people/rahul/full.sht $\underline{m l}$.

6) Jhon Scott and Gordon Marshall, A Dictionary of Sociology, Oxford University Press, 2009, p.230

7) Asar Chowdhury, Book Review, The Hungry Tide by Amitav Ghosh,25April,2011 http://www.thedailystar.net/2004/11/27/d411272102 $\underline{100 . h t m}$ 